\title{
Tourniquet-Free Hand Surgery Using the One-per-Mil Tumescent Technique
}

\author{
Theddeus O. H. Prasetyono \\ Division of Plastic Surgery, Department of Surgery, Cipto Mangunkusumo Hospital, Faculty of Medicine Universitas Indonesia, Jakarta, \\ Indonesia
}

Background A pneumatic tourniquet is generally used to achieve a bloodless operation field in hand surgery. However, this has changed with tumescent solution-based wide-awake surgery. This study is a preliminary prospective case series study to elaborate the formula and indications of the tumescent technique in hand surgery without a tourniquet.

Methods Seven patients (age range, 4 months to 37 years) underwent hand or upper extremity surgery for conditions such as nerve palsy, electric burn defect, fingertip injury, contracture, constriction ring syndrome, or acrosyndactyly. A "one-per-mil" tumescent solution (epinephrine $1: 1,000,000+20 \mathrm{mg}$ lidocaine $/ 50 \mathrm{~mL}$ saline) was used to create a bloodless operating field without a tourniquet. Observation was performed to document the amount of solution injected, the operation field clarity, and the postoperative pain.

Results The "one per mil" epinephrine solution showed an effective hemostatic effect. The tumescent technique resulted in an almost bloodless operation field in the tendon and in the constriction ring syndrome surgeries, minimal bleeding in the flap and contracture release surgeries, and acceptable bleeding in acrosyndactyly surgery. The amount of solution injected ranged from 5.3 to $60 \mathrm{~mL}$. No patient expressed significant postoperative pain. Flap surgeries showed mixed results. One flap was lost, while the others survived.

Conclusions Epinephrine 1:1,000,000 in saline solution is a potential replacement for a tourniquet in hand surgery. Further studies are needed to delineate its safety for flap survival.

Keywords Epinephrine / Lidocaine / Upper extremity
Correspondence:

Theddeus 0. H. Prasetyono

Division of Plastic Surgery,

Department of Surgery, Cipto Mangunkusumo Hospital, Faculty

of Medicine Universitas Indonesia Medical Staff Building, 4th floor, Jl. Diponegoro 71, Jakarta 13410, Indonesia

Tel: +62-817858899

Fax: +62-21-31931424

E-mail: teddyohprasetyono@yahoo. com

This article was presented at the 4 th International Symposium on Hand Surgery and the Advances of Hand Therapy on February 17-18, 2011 in Bandung, Indonesia.

No potential conflict of interest relevant to this article was reported.

Received: 28 Nov 2012 • Revised: 17 Jan 2013 • Accepted: 19 Jan 2013

pISSN: 2234-6163 • elSSN: 2234-6171 • http://dx.doi.org/10.5999/aps.2013.40.2.129 • Arch Plast Surg 2013;40:129-133

\section{INTRODUCTION}

Wide-awake hand surgery, mostly on tendon structures, under local anesthesia with tumescent solution has been widely performed in North America [1-5]. Interestingly, this tumescent solution-based wide-awake hand surgery has challenged the dogma of the conservative approach. It allows surgeons to perform the operation under local anesthesia without interfering with the recognition of the tendons and other structures [2-9].
The epinephrine concentration used is in the range of $1: 80,000$ to $1: 400,000$. This study was a preliminary case series conducted to elaborate the use of a 1:1,000,000 tumescent formula and other clinical indications of the tumescent technique.

\section{METHODS}

A prospective case series study was conducted during the period of December 2010 to March 2011. A tumescent solution 
comprising an epinephrine concentration of 1:1,000,000 ("oneper-mil”) in saline solution, added to a $20 \mathrm{mg}$ lidocaine per 50 $\mathrm{mL}$ solution, was injected locally to create a bloodless operation field for hand and upper extremity surgery without a pneumatic tourniquet (Fig. 1). The tumescent solution was injected into the tissue until the skin turned pale. We report on seven cases, but with one patient who underwent surgery with general anesthesia.

Observation was performed for note-taking on the amount of tumescent solution injected, the clarity of the operation field, the length of the surgery, and the subsequent pain on postoperative day one. The clarity of the operation field was subjectively evalu-

\section{Fig. 1. Injection to a burn hand contracture in a child}

In case 3, a 12-month-old baby presented with four-finger flexion contracture due to a burn. Injection of the tumescent solution was performed, reaching a total of $5.3 \mathrm{~mL}$, to create a clear operation field without a tourniquet.

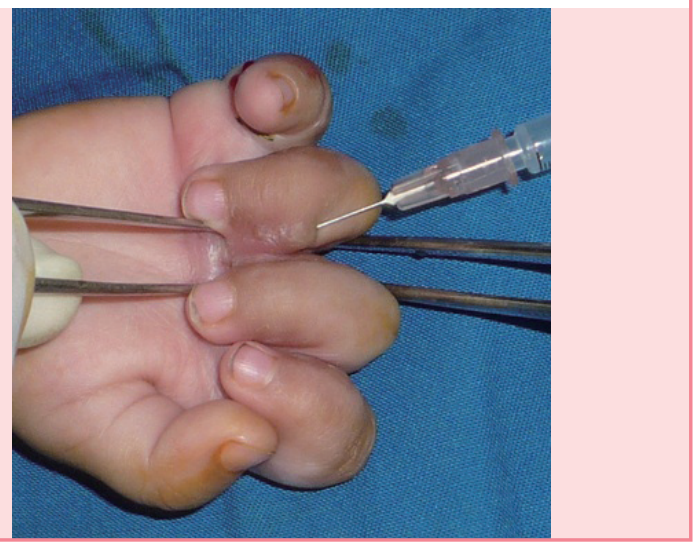

ated by dividing the field into the following three categories: totally bloodless, minimum bleeding, and acceptable bleeding. The totally bloodless category includes a bloodless operation field condition that is similar to that achieved by using a pneumatic tourniquet. Minimum bleeding is defined as bleeding in the operation field that does not hinder the recognition of the anatomical structures and does not need frequent blood sweeping with gauze. Acceptable bleeding represents a condition that needs more frequent blood sweeping in order to preserve the anatomical recognition, but does not hamper performing complicated surgical procedures. Post-operative pain was subjectively measured with a verbal rating scale (VRS) for the adult patients, while the face legs activity cry consolability (FLACC) behavioral pain assessment scale was used for infants and young children $[10,11]$. The pain severity level of the VRS is scored as 0 for no pain, 1 for mild pain, 2 for moderate pain, 3 for severe pain, and 4 for very severe pain. In the FLACC scale, each of the 5 categories is scored from 0 to 2 , resulting in a total score between 0 to 10 .

\section{RESULTS}

Table 1 shows the patients' demographics with the subsequent type of surgery, volume of the tumescent solution used, and the clarity of the operation field. Three of the seven cases showed a totally bloodless operation field similar to the field under tourniquet control (Fig. 2). The "one-per-mil" tumescent solution successfully created minimum bleeding in the other 3 cases. In case 7, finger separation and web reconstruction in acrosyndactyly

Table 1. Patients' demographics with the subsequent type of surgery, volume of the tumescent solution, and clarity of the operation field

\begin{tabular}{|c|c|c|c|c|c|c|c|c|c|}
\hline No & Age & Sex & Problem & Type of surgery & $\begin{array}{l}\text { Type of } \\
\text { anes- } \\
\text { thesia }\end{array}$ & $\begin{array}{l}\text { Volume of } \\
\text { tumescent }(\mathrm{mL})\end{array}$ & $\begin{array}{c}\text { Clarity of } \\
\text { operating field }\end{array}$ & $\begin{array}{l}\text { Length } \\
\text { of } \\
\text { surgery } \\
\text { (min) }\end{array}$ & $\begin{array}{l}\text { Pain scale on } \\
\text { postop day } 1\end{array}$ \\
\hline 1 & $21 \mathrm{yr}$ & $M$ & Chronic ulnar palsy & Tendon transfer & GA & 55 & Totally bloodless & 105 & VRS: mild \\
\hline 2 & $37 \mathrm{yr}$ & M & $\begin{array}{l}\text { Forearm defect after } \\
\text { an electric burn }\end{array}$ & $\begin{array}{l}\text { Radial forearm perforator } \\
\text { flap }\end{array}$ & GA & 60 & Minimum bleeding & 75 & VRS: mild \\
\hline 3 & $12 \mathrm{mo}$ & M & $\begin{array}{l}\text { Four finger flexion } \\
\text { contracture }\end{array}$ & $\begin{array}{c}\text { Contracture release and } \\
\text { FTSG }\end{array}$ & GA & 5.3 & Minimum bleeding & 170 & FLACC: 3 \\
\hline 4 & $4 \mathrm{mo}$ & M & $\begin{array}{l}\text { Upper arm constriction } \\
\text { ring syndrome }\end{array}$ & $\begin{array}{c}\text { Circumferential } \\
\text { constriction release }\end{array}$ & GA & 17 & Totally bloodless & 140 & FLACC: 0 \\
\hline 5 & $57 \mathrm{yr}$ & M & $\begin{array}{l}\text { Four finger extension } \\
\text { contracture }\end{array}$ & $\begin{array}{c}\text { Contracture release and } \\
\text { FTSG }\end{array}$ & GA & 47 & Minimum bleeding & 205 & VRS: mild \\
\hline 6 & $30 \mathrm{yr}$ & M & $\begin{array}{l}\text { Dorsal composite tissue } \\
\text { loss of the thumb }\end{array}$ & Kite flap & LA & $\begin{array}{c}26 \text { (14 for thumb; } \\
12 \text { for flap donor area) }\end{array}$ & $\begin{array}{l}\text { Totally bloodless for flap } \\
\text { dissection; minimum } \\
\text { bleeding for recipient }\end{array}$ & 80 & VRS: mild \\
\hline 7 & $10 \mathrm{mo}$ & M & $\begin{array}{l}\text { Acrosyndactyly in } \\
\text { Apert syndrome }\end{array}$ & $\begin{array}{l}\text { 1st web release, fingers } \\
\text { separation with } \\
\text { pentagonal island flaps, } \\
\text { and FTSG }\end{array}$ & GA & $\begin{array}{l}11.4 \text { ( } 3 \text { for } 1 \text { st web; } \\
3.4 \text { for index and middle } \\
\text { fingers; } 5 \text { for ring and } \\
\text { little fingers) }\end{array}$ & Acceptable bleeding & 205 & FLACC: 3 \\
\hline
\end{tabular}




\section{Fig. 2. A totally bloodless operation in an arm of a baby}

In case 4, as shown in Fig. 2, (A) a totally bloodless operation field was successfully made using $17 \mathrm{~mL}$ of "one-per-mil" tumescent solution during 140 minutes of constriction release. (B) The results after constriction release postoperative day 12 .
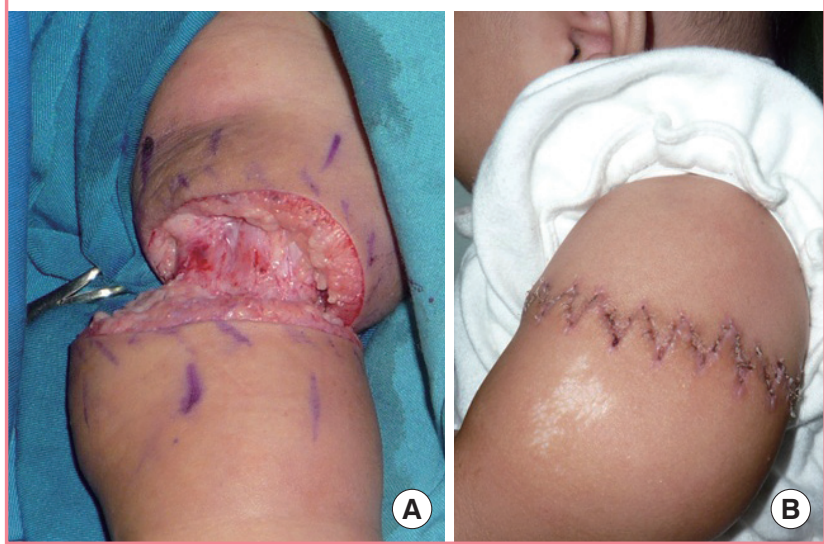

\section{had acceptable bleeding.}

In case 2, the perforator-based radial forearm flap resulted in partial necrosis. The remaining raw surface was then covered with a split-thickness skin graft. Subsequently, the kite flap of case 6 was lost. However, in case 7, 2 dorsal pentagonal island flaps for creating web space survived well.

\section{DISCUSSION}

The history of the use of a tourniquet device includes devastating complications. Since the introduction of the pneumatic tourniquet, which was intended to alleviate potential complications, there have been reports of major complications such as compartment syndrome, which resulted in limitation of limb movement, limb paralysis, and even massive rigor [12-14]. Several reports have shown the disastrous effects of a low profile tourniquet, such as rubber tubes, causing prolonged finger ischemia and catastrophic toe necrosis [15-19].

The application of a tourniquet has been reported to cause ischemia in cases ranging from 20 minutes to more than 4 days, or thumb necrosis in a case where the tourniquet was forgotten and left in place for 7 days $[15,18,20]$. Unfortunately, the incidence of finger ischemia due to a forgotten digital tourniquet seems to be occur from time to time, as was reported in 2011 [17]. In addition, case 4 showed that a tourniquet cannot be used in particular areas of the upper extremity without hindering the surgical procedure (Fig. 3). Based on the facts from the reports mentioned above, our study is an important contribution to the literature on hand surgery without a tourniquet.

This study is an elaboration of previous reports and studies on wide-awake hand surgery using a tumescent solution with a con-

\section{Fig. 3. A totally bloodless operation in an arm of a baby}

In case 4, a 4-month-old male presented with a circumferential constriction ring in his left proximal upper arm. In this case, we determined that it would be almost impossible to set the tourniquet without hindering the operation.

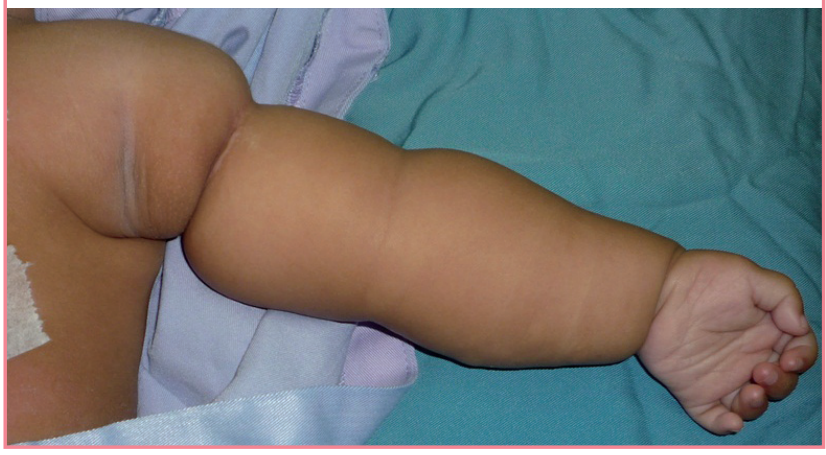

centration of epinephrine ranging from 1:100,000 to 1:400,000 [2-4]. Although the 1:100,000 epinephrine concentration has been widely accepted as safe and effective, our study shows that a concentration of 10 times less was also effective and even safer. In this study, a true tumescent technique was used, in which the solution was applied to expand the subcutaneous tissue, in contrast to previous studies that have used the solution to perform a digital nerve block $[2,21]$. The volume of the tumescent solution injected into the patient was excessive. For example, a $5 \mathrm{~mL}$ solution is considered massive for treating the fingers of an infant, while a $17 \mathrm{~mL}$ solution is considered an enormous amount for treating a ring constriction of an arm of a 4-month-old infant.

Unlike the previous studies that used a tumescent solution mainly as an anesthetic agent, this study emphasized the use of a tumescent solution for creating a bloodless operation field $[2,3,21]$. Therefore, epinephrine is the vital component of the solution, while lidocaine only functions as a multimodal analgesic. For this reason, the lidocaine does not influence the amount of tumescent solution that should be injected. For surgery under local anesthesia, lidocaine plays an important role. The amount of injected tumescent solution ranged from 5.3 to $60 \mathrm{~mL}$. Every $50 \mathrm{~mL}$ of tumescent solution contained $20 \mathrm{mg}$ of lidocaine. The calculated amount of lidocaine used in this study ranged from 2.12 to $24 \mathrm{mg}$.

Most of the patients in this study underwent operations under general anesthesia for the following reasons. The first patient preferred general anesthesia to local anesthesia. The second patient required complex procedures on both of his arms. The fifth patient had a massive burn contracture with the potential for immense pain when the tumescent solution was injected in the fibrotic area with dense tissue. The other patients were infants who required general sedation.

Regarding the injection volume, it seems that the "one-per-mil" 
solution offered a higher degree of safety, because this concentration is considered to be very safe. In an in-depth review of 59 cases of finger injection with a high dose $(1: 1,000)$ of epinephrine, there was no finger necrosis with or without treatment [22]. However, Thomson et al. [23] predicted that reports of finger infarction in the future are inevitable. In fact, a "one-per-mil" epinephrine solution can also be seen as an anticipatory response to Thomson's prediction.

With regard to indication, this study broadens the possibility for applying a "one-per-mil" tumescent solution without a tourniquet in various types of pathology, and not only for tendon surgery. Injecting the solution into the scar tissue is challenging because the scar tissue is much denser, such as in a hypertrophic scar. Using a new needle for every injection may be helpful for reducing the resistance of the dense tissue. However, injecting the tumescent solution has to be performed with extra care for flap surgery, especially for a perforator flap. Total necrosis of a kite flap may be caused by technical factors and not necessarily by the tumescent solution. Partial necrosis of a perforator radial forearm flap challenges whether the tumescent solution should be avoided in perforator-based flap surgery. This study shows that it should be avoided because multiple needle insertions while injecting the solution may injure the perforator vessel.

Epinephrine at a concentration of 1:1,000,000 in a saline solution (a "one-per-mil" tumescent solution) is a potentially excellent replacement for a pneumatic tourniquet for surgeries in the upper extremities, an infant's hand, and an area with scar tissue. However, it might not be well suited for harvesting a perforatorbased flap. Further studies are needed to delineate the safety of the tumescent injection for flap survival.

\section{REFERENCES}

1. Lalonde DH, Lalonde JF. Discussion. Do not use epinephrine in digital blocks: myth or truth? Part II. A retrospective review of 1111 cases. Plast Reconstr Surg 2010;126:2035-6.

2. Lalonde DH. "Hole-in-one" local anesthesia for wide-awake carpal tunnel surgery. Plast Reconstr Surg 2010;126:1642-4.

3. Higgins A, Lalonde DH, Bell M, et al. Avoiding flexor tendon repair rupture with intraoperative total active movement examination. Plast Reconstr Surg 2010;126:941-5.

4. Bezuhly M, Sparkes GL, Higgins A, et al. Immediate thumb extension following extensor indicis proprius-to-extensor pollicis longus tendon transfer using the wide-awake approach. Plast Reconstr Surg 2007;119:1507-12.

5. Denkler K. Dupuytren's fasciectomies in 60 consecutive digits using lidocaine with epinephrine and no tourniquet. Plast Reconstr Surg 2005;115:802-10.
6. Wilhelmi BJ, Blackwell SJ, Miller JH, et al. Do not use epinephrine in digital blocks: myth or truth? Plast Reconstr Surg 2001;107:393-7.

7. Chowdhry S, Seidenstricker L, Cooney DS, et al. Do not use epinephrine in digital blocks: myth or truth? Part II. A retrospective review of 1111 cases. Plast Reconstr Surg 2010;126:2031-4.

8. Lalonde $\mathrm{D}, \mathrm{Bell} \mathrm{M}$, Benoit $\mathrm{P}$, et al. A multicenter prospective study of 3,110 consecutive cases of elective epinephrine use in the fingers and hand: the Dalhousie Project clinical phase. J Hand Surg Am 2005;30:1061-7.

9. Lalonde DH. An evidence-based approach to flexor tendon laceration repair. Plast Reconstr Surg 2011;127:885-90.

10. Ohnhaus EE, Adler R. Methodological problems in the measurement of pain: a comparison between the verbal rating scale and the visual analogue scale. Pain 1975;1:379-84.

11. Merkel SI, Voepel-Lewis T, Shayevitz JR, et al. The FLACC: a behavioral scale for scoring postoperative pain in young children. Pediatr Nurs 1997;23:293-7.

12. Luk KD, Pun WK. Unrecognised compartment syndrome in a patient with tourniquet palsy. J Bone Joint Surg Br 1987; 69:97-9.

13. Hirvensalo E, Tuominen H, Lapinsuo M, et al. Compartment syndrome of the lower limb caused by a tourniquet: a report of two cases. J Orthop Trauma 1992;6:469-72.

14. Knuttgen D, Reifenrath W, Autze W, et al. Massive rigor and compartment syndrome after tourniquet in a patient with suspected malignant hyperthermia. Acta Anaesthesiol Scand 1999;43:239-40.

15. Dove AF, Clifford RP. Ischaemia after use of finger tourniquet. Br Med J (Clin Res Ed) 1982;284:1162-3.

16. Karabagli Y, Kose AA, Cetin C. Toe necrosis due to a neglected tourniquet. Plast Reconstr Surg 2005;116:2036-7.

17. Selvan D, Harle D, Fischer J. Beware of finger tourniquets: a case report and update by the National Patient Safety Agency. Acta Orthop Belg 2011;77:15-7.

18. Durrant $C$, Townley WA, Ramkumar $S$, et al. Forgotten digital tourniquet: salvage of an ischaemic finger by application of medicinal leeches. Ann R Coll Surg Engl 2006;88:462-4.

19. Avci G, Akan M, Yildirim S, et al. Digital neurovascular compression due to a forgotten tourniquet. Hand Surg 2003;8: 133-6.

20. Hou SM, Liu TK. Salvage of tourniquet-induced thumb necrosis by a modified wraparound procedure. J Trauma 1987;27:803-5.

21. Lalonde DH. Reconstruction of the hand with wide awake surgery. Clin Plast Surg 2011;38:761-9.

22. Fitzcharles-Bowe C, Denkler K, Lalonde D. Finger injection 
with high-dose $(1: 1,000)$ epinephrine: Does it cause finger necrosis and should it be treated? Hand (NY) 2007;2:5-11.

23. Thomson CJ, Lalonde DH, Denkler KA, et al. A critical look at the evidence for and against elective epinephrine use in the finger. Plast Reconstr Surg 2007;119:260-6. 